\title{
Lucha e institucionalización: dos dimensiones de la justicia social como reconocimiento en el pensamiento de Axel Honneth *
}

\author{
Struggle and Institutionalization: Two Dimensions of Social Justice as \\ Recognition in the Thinking of Axel Honneth
}

\author{
Por: Toninello, Emilse* \\ (IIGG/CONICET) \\ Buenos Aires, Argentina
}

Email: emilse_toninello@hotmail.com

Fecha de recepción: 30/09/2021

Fecha de aprobación: 14/10/2021

DOI: https://doi.org/10.30972/nvt.1725715

\section{Resumen}

Este artículo se dedicará a los desarrollos de Axel Honneth, se abordará especialmente La lucha por el reconocimiento, ¿Redistribución o reconocimiento? Y El derecho de la libertad, con el objetivo de aproximarse a su consideración en torno a la justicia social como reconocimiento. Ante lecturas críticas que han sostenido un desplazamiento o abandono de la centralidad del conflicto en la obra de Honneth, dándole mayor importancia a la dimensión institucional, esto es, una desatención al concepto de lucha a efectos de un mayor interés en la institucionalidad de la vida social, aquí se propone una lectura alternativa fundada en la idea de la coexistencia de dos tiempos en la teoría de Axel Honneth: lucha e institucionalización, constituyen dos dimensiones igualmente importantes de la comprensión honnethiana de la justicia social.

\footnotetext{
* Este texto se inscribe en el marco de la realización de mi tesis de maestría en el programa de la Maestría en Teoría Política y Social (UBA), en la cual me encuentro emprendiendo una reconstrucción normativa de la noción de justicia social en la Argentina, desde una perspectiva teórico-política.

* Licenciada en Ciencia Política por la Universidad de Buenos Aires. Becaria doctoral Conicet, con sede de trabajo en el Instituto de Investigaciones Gino Germani de la Facultad de Ciencias Sociales (UBA). Docente en la materia "Teorías sobre el poder", en la carrera de Ciencia Política de la Facultad de Ciencias Sociales (UBA).
} 
Lucha e institucionalización: dos dimensiones de la justicia social como

reconocimiento en el pensamiento de Axel Honneth

Palabras clave: Lucha- Institucionalización- Justicia Social- Reconocimiento- Axel Honneth

\section{Abstract}

This article will be dedicated to the developments of Axel Honneth, The struggle for recognition, Redistribution or recognition?, And The right to freedom, with the aim to approaching the consideration of it around social justice as recognition. Faced with critical readings that have sustained a displacement or abandonment of the centrality of the conflict in Honneth's work, giving greater importance to the institutional dimension, that is, a disregard for the concept of struggle for the purpose of greater interest in the institutionality of life social, here an alternative reading is proposed based on the idea of the coexistence of two times in Axel Honneth's theory: struggle and institutionalization constitute two equally important dimensions of Honneth's understanding of social justice.

Keywords: Struggle-Institutionalization- Social Justice- Recognition- Axel Honneth

\section{Cómo citar este artículo:}

APA: Toninello, E. (2021). Lucha e institucionalización: dos dimensiones de la justicia social como reconocimiento en el pensamiento de Axel Honneth. Nuevo Itinerario, 17 (2), 97-126. Recuperado de: (agregar dirección web)

\section{Introducción}

\section{a. La justicia como problema permanente}

La pregunta por el orden social justo puede ser encontrada bajo diversas formulaciones a lo largo de toda la tradición de pensamiento político occidental. Tal como ha indicado Leo Strauss, no es posible conocer las cosas políticas "si no se toma en serio su implícita o explícita exigencia de ser juzgadas en términos de bondad o maldad, de justicia o injusticia..." (2014: 83). Así, la justicia del ordenamiento político 


\section{Emilse Toninello}

se

encuentra en el centro tanto de las reflexiones clásicas como también de las contemporáneas. Ante la permanente pregunta por lo justo han proliferado una multiplicidad de respuestas. Sin embargo, esta diversidad solo sería indicativa de su carácter problemático y, por tanto, la necesidad de continuar reflexionando sobre ellos (Strauss, 2014). ${ }^{1}$

De Platón ${ }^{2}$ a Kant ${ }^{3}$, pasando por Hobbes ${ }^{4}$-por nombrar solo algunas referencias- se ha procurado ofrecer respuestas a la pregunta por lo justo. Asimismo, las líneas de pensamiento abiertas por la filosofía de la temprana modernidad fueron parcialmente tomadas y modificadas en las reflexiones volcadas en la Teoría de la justicia de John Rawls (2018), quien, sin dudas, produjo una revitalización del debate por la justicia en el pensamiento político contemporáneo.

En discusión con la tradición utilitarista, el autor estadounidense sostuvo que otra concepción de la justicia era posible si se generalizaba y se elevaba el nivel de abstracción de las teorías del contrato, centralmente las que fueran elaboradas por

\footnotetext{
* Este texto se inscribe en el marco de la realización de mi tesis de maestría en el programa de la Maestría en Teoría Política y Social (UBA), en la cual me encuentro emprendiendo una reconstrucción normativa de la noción de justicia social en la Argentina, desde una perspectiva teórico-política.

${ }^{1}$ Sobre una mirada de conjunto a la perspectiva de la Historia de las ideas, ver Castorina, F. y Wieczorek, T. (2020). "Historia de las ideas". En Nosetto, L. y Wieczorek, T. (2020). Métodos de teoría política. Un manual. Ciudad Autónoma de Buenos Aires: Universidad de Buenos Aires. Instituto de Investigaciones Gino Germani.

${ }^{2}$ En el pensamiento clásico griego, si bien Platón definió a la justicia como aquella unión armónica donde cada individuo ocupaba el lugar que le correspondía (Sabine, 1982); y Aristóteles, en cambio, concibió la justicia como una virtud de la comunidad en su conjunto, es posible decir que en ambos autores, la justicia estaba asociada con la comprensión de la igualdad entre iguales y la desigualdad entre desiguales (Penchaszadeh, 2011). Ver Platón. (2009). República. Buenos Aires: Eudeba. Ver también Aristóteles. (2007). Política. Buenos Aires: Alianza.

${ }^{3}$ Immanuel Kant, sin desarrollar una teoría de la justicia, ha elaborado una concepción que hasta la actualidad continúa calando en las reflexiones teórico-políticas. Tal como señala Marcelo Raffin, en Kant (2012), "la idea de justicia aparece como la resultante de tres aspectos de su manera de concebir el mundo humano: el contrato, que da nacimiento al Estado; su visión del mundo moral y del reino de la libertad con la lógica de la ley moral; y la actividad del juez y del juicio judicial en tanto intermediario entre el Estado y la libertad individual como garante de la libertad de todos" (2012: 119). Ver Kant, I. (2009). Crítica de la razón pura. México: Fondo de Cultura Económica.

${ }^{4}$ Thomas Hobbes le ha dedicado buena parte de sus análisis al concepto de justicia que, no obstante, mantiene una pluralidad de sentidos (Vázquez Prieto, 2011). Al menos dos nociones pueden encontrarse en la obra hobbesiana: una, la justicia de los actos, asociada al cumplimiento de la ley positiva; otra noción, la justicia de los hombres, relacionada con las intenciones, los propósitos y los motivos. Mientras la primera pertenece al foro externo, la segunda es parte del foro interno. Si bien ciertas interpretaciones posteriores han privilegiado un sentido ante otro, es posible considerar que ambos se encuentran en una articulación tensa en la cual coexisten sin excluirse (Vázquez Prieto, 2011). Ver Hobbes, T. (2007). Leviatán. Buenos Aires: Losada.
} 
Lucha e institucionalización: dos dimensiones de la justicia social como reconocimiento en el pensamiento de Axel Honneth

John Locke, Jean Jacques Rousseau e Immanuel Kant (Rawls, 2018). Su objetivo fue formular una teoría de la justicia como imparcialidad, bajo la cual se alcancen acuerdos básicos sobre los principios que ordenarán el modo de asignar derechos y deberes en las instituciones sociales. Este acuerdo inicial será, pues, el que regule todos los acuerdos posteriores y por ello debe realizarse en condiciones justas. La garantía de las condiciones justas a la hora de acordar los principios que regirán el ordenamiento social está dada por lo que el autor ha denominado "posición original": se trata del estado inicial por el cual se aseguran acuerdos imparciales. Rawls sostiene que esta posición es puramente hipotética -al igual que el estado de naturaleza de las teorías contractuales- y que en ella los miembros de una comunidad pueden despojarse de sus posiciones sociales, culturales, simbólicas, materiales, etc. para deliberar libremente y decidir racionalmente los principios de justicia que distribuirán los derechos y obligaciones, sin obtener ventajas por la posición que se ocupe en la sociedad (Rawls, 2018). La publicación de este texto ha suscitado tanto partidarios como adversarios, y ha dado lugar a extensas producciones académicas al respecto.

\section{b. Aproximaciones contemporáneas al debate sobre la justicia social}

Más recientemente, Axel Honneth y Nancy Fraser han trabado un debate en torno a la comprensión de la justicia social, en cuyas argumentaciones -más allá del contrapunto entre sí-, pueden advertirse la interlocución y los desacuerdos respecto de la teoría rawlsiana. En este debate, signado por la pregunta “¿redistribución o reconocimiento?" (Fraser y Honneth, 2006), Nancy Fraser sostuvo que la justicia exige tanto redistribución como reconocimiento, ya que ninguna de ellas por separado resulta suficiente. De modo que, funda su propuesta en una concepción bidimensional, que contenga reivindicaciones económicas y culturales como dimensiones que mantienen una independencia relativa entre sí pero que interactúan. La autora indica que la cuestión del reconocimiento, lejos de vincularse con la autorrealización, está estrechamente relacionada con la estima social y, por ello, un reconocimiento erróneo se caracteriza por la negación de la posibilidad de participar en la interacción social en igualdad de condiciones. Por ello, ofrece la noción de paridad participativa, como núcleo normativo de su modelo, según el cual la justicia exige unos acuerdos sociales 


\section{Emilse Toninello}

que les permita a todos los miembros de la sociedad interactuar en pie de igualdad (Fraser y Honneth, 2006).

En cambio, para Axel Honneth, es la reactualización teórica del concepto hegeliano de reconocimiento lo que permite la comprensión de los conflictos sociales, ya que advierte en ellos una motivación ética y no solo material o simbólica. Y porque comprende que la sociedad burguesa capitalista se estructura como un orden institucionalizado de reconocimiento con tres esferas históricamente diferenciadas, es que la noción de reconocimiento se vuelve crucial para el abordaje político de la justicia. Honneth considera que el progreso moral está vinculado a la expansión e intensificación del reconocimiento en las esferas y entre ellas (Honneth, 2006).

Este somero recorrido, que espera ser eximido de las exigencias de exhaustividad, funge de indicio de la relevancia y la permanencia del problema de la justicia para la vida en común. Por todo ello, este artículo se dedicará a los desarrollos de Axel Honneth, con el objetivo de aproximarse a su consideración en torno a la justicia social como reconocimiento. Ante lecturas críticas que han sostenido un desplazamiento o abandono de la centralidad del conflicto en la obra de Honneth, dándole mayor importancia a la dimensión institucional ${ }^{5}$, esto es, una desatención al concepto de lucha a efectos de un mayor interés en la institucionalidad de la vida social, aquí se propone una lectura alternativa fundada en la idea de la coexistencia de dos tiempos en la teoría de Axel Honneth: lucha e institucionalización, constituyen dos dimensiones igualmente importantes de la comprensión honnethiana de la justicia social.

\footnotetext{
${ }^{5}$ Francisco Abril, apoyado en las consideraciones de Ludwig Siep, sostiene que si bien en las reconstrucciones históricas realizadas por Honneth, la importancia de la lucha resulta ostensible, se puede observar una insuficiente tematización en términos teóricos y normativos del concepto de lucha, que sí poseía en sus trabajos previos. Dice Abril: “...a diferencia de los textos del ' 80 y ' 90 , en este último libro [El derecho de la libertad] no hay una consideración teórico-normartiva sobre la relevancia de la idea de "lucha" [...] En su último libro, por el contrario, centra todo su esfuerzo teórico en aclarar la noción e importancia del reconocimiento y la libertad social que, dicho sea de paso, se entienden como instancias libradas de conflicto" (2016: 7). El autor aclara que no se trata de un completo abandono de la lucha por parte de Honneth, pero advierte que este cambio de énfasis no contribuye al desarrollo de una teoría crítica de la dominación. Ver Abril, F. (2016). El problema de la dominación en El derecho de la libertad de Axel Honneth. Revista Pilquen (19), 1, pp. 1-12.
} 
Lucha e institucionalización: dos dimensiones de la justicia social como

reconocimiento en el pensamiento de Axel Honneth

Para ello, en el primer apartado se procederá a restituir las consideraciones de Honneth sobre el reconocimiento como lucha, en cuya exposición se retoman las elaboraciones tempranas de Hegel sobre el asunto. Aunque allí también aparecen menciones a la importancia de las instituciones en las relaciones de reconocimiento recíproco, a los fines de mantener la claridad expositiva, aquí solo se señalará la relevancia de la noción de lucha en las relaciones de reconocimiento, y su centralidad para la realización de la justicia. Luego, en el segundo apartado se iluminará el énfasis dado por el autor a la dimensión institucional, centralmente en su debate con Nancy Fraser y en una de sus últimas publicaciones: El derecho de la libertad. Finalmente, se concluirá que tanto el momento de la lucha como el de la institucionalización constituyen dos dimensiones igualmente importantes, ya que son susceptibles de ser encontradas en toda la obra del autor, con distintos énfasis. Así, se puede observar que en los primeros escritos la lucha es colocada en el centro de su teoría mientras que en sus últimos estudios la centralidad fue tomada por la dimensión institucional. No obstante, aquí se sostendrá que ambas resultan cruciales en la teoría de la justicia social elaborada por Axel Honneth, y se sustentará dicha afirmación a partir del trabajo restitutivo e interpretativo de los textos más emblemáticos del autor.

\section{El reconocimiento como lucha}

El concepto de reconocimiento se ha vuelto decisivo, según Axel Honneth, para analizar las sociedades capitalistas contemporáneas. A estos fines, el autor ha emprendido una reactualización del pensamiento político de Hegel, y desde los comienzos de sus reflexiones hasta la actualidad, se ha propuesto elaborar una teoría normativa de la sociedad (1997, 2006, 2016). En lo que sigue, se restituirá sucintamente el recorrido propuesto en los escritos de Honneth, haciendo énfasis en aquellos elementos que aporten mayor claridad a la noción de lucha por el reconocimiento ${ }^{6}$, cuya centralidad en la teoría de la justicia del autor resulta insoslayable. $^{7}$

\footnotetext{
${ }^{6}$ Reflexiones en torno al reconocimiento en el marco de una reactualización del pensamiento hegeliano, puede consultarse Taylor, C. (2009). El multiculturalismo y "La política del reconocimiento". México: Fondo de Cultura Económica. Ver también, Kojève, a. (2013). Introducción a la lectura de Hegel. Madrid:
} 


\section{Emilse Toninello}

En La lucha por el reconocimiento (1997), Honneth recupera los escritos tempranos de Hegel porque considera que aún constituyen un potente marco conceptual para la teoría social. En efecto, desde el comienzo del libro, cuyo origen es la tesis de habilitación del autor, se sostiene que, desde su juventud, Hegel elaboró un instrumento teórico que afirma que la lucha por el reconocimiento recíproco entre los sujetos requiere la aceptación de un conjunto de instituciones que garanticen la libertad individual. Asimismo, la pretensión de los individuos de obtener un reconocimiento intersubjetivo se erige como una tensión moral que luego sobrepasa lo ya institucionalizado, posibilitando así el progreso moral. Aquí, Honneth Ilama la atención sobre el giro que se ha producido en la teoría hegeliana en torno a la noción de lucha social ${ }^{8}$ que pueden ser encontradas en desarrollos teóricos previos, tales como los de Nicolás Maquiavelo y Thomas Hobbes. En tal sentido, Hegel difiere de sus predecesores en la medida en que comprende que los conflictos sociales están referidos a motivaciones morales, más que a la búsqueda de la autoconservación (Honneth, 1997), y es este el punto de partida que toma Honneth para su estudio sobre la gramática moral de los conflictos sociales contemporáneos.

En discusión con las modernas doctrinas del derecho natural ${ }^{9}$, Hegel emprende una construcción filosófica que le ha permitido pensar la conexión ética de todos los ciudadanos a partir del ejercicio del reconocimiento solidario de la libertad individual de cada uno de ellos (Honneth, 1997). A estos fines, en primer lugar, sustituye la

Editorial Trotta. En una dirección distinta a la de Axel Honneth, puede verse en Ricouer, P. (2006). Caminos del reconocimiento. México: Fondo de Cultura Económica. Ver también, Butler, J. (2012). Sujetos del deseo. Reflexiones hegelianas en la Francia del siglo XXI. Buenos Aires: Amorrortu; Butler, J. (2010). Marcos de guerra. Las vidas lloradas. Buenos Aires: Paidós; Butler, J. (2017). Deshacer el género. España: Paidós.

${ }^{7}$ En el presente apartado se emprenderá una estrategia de lectura siguiendo las prescripciones de la hermenéutica. Ver Fraile, N. y Kiel, R. (2020). “Hermenéutica”. En Nosetto, L. y Wieczorek, T. (2020). Métodos de teoría política. Un manual. Ciudad Autónoma de Buenos Aires: Universidad de Buenos Aires. Instituto de Investigaciones Gino Germani.

8 Sobre el concepto de lucha por el reconocimiento y su vinculación con los desarrollos de Thomas Hobbes, ver Siep, L. (2011). La lucha por el reconocimiento. La relación entre Hegel y Hobbes en los escritos de Jena. Estudios de Filosofía. Universidad de Antioquia (43), pp. 31-84.

${ }^{9}$ Sobre la relación de Hegel con la tradición del derecho natural, ver Bobbio, N. (1989). Hegel y el iusnaturalismo. En Amengual Coll, G. (1989). Estudios sobre la Filosofía del Derecho de Hegel. Madrid: Centro de Estudios Constitucionales 
Lucha e institucionalización: dos dimensiones de la justicia social como

reconocimiento en el pensamiento de Axel Honneth

consideración del individuo como un ser aislado, por categorías que privilegien la conexión ética de los miembros de la comunidad. Seguidamente, remarca el carácter conflictivo que caracteriza el pasaje de una eticidad natural a una comunidad ética, en la cual las relaciones éticas se liberan de las unilateralidades y las particularidades luego de un proceso de negaciones recurrentes. Hegel comprende, entonces, el "devenir de la eticidad como una progresiva expresión de lo negativo o subjetivo" (Honneth, 1997: 26).

Por tanto, se podría afirmar que, para Hegel, los individuos, en tanto miembros de una comunidad ética, pretenden y exigen un reconocimiento, por medio de la lucha, que es necesariamente intersubjetivo. De manera que, el sujeto deviene como tal en la medida en que se sabe reconocido por otros en sus cualidades y facultades. Es así como el sujeto conoce diversas partes o aspectos de sí mismo y adquiere mayor conciencia de su particularidad. En esta estructura básica del reconocimiento recíproco, es posible avizorar, por un lado, que en el momento del reconocimiento existe un reencuentro o reconciliación con el otro y, por otro lado, se produce una contraposición con él en la distinción de su especificidad (Honneth, 1997). Tal como indica Honneth: "[e]I movimiento de reconocimiento, que subyace en la relación ética entre los sujetos consiste en un proceso de etapas de reconciliación y de conflictos, separados unos de otros" (1997: 28). En tal sentido, la concepción de la lucha se modifica en tanto se vuelve un acontecimiento ético, ya que, de esa manera, se expande el reconocimiento subjetivo de las dimensiones de la individualidad humana (Honneth, 1997: 29). Asimismo, cabe señalar que para Honneth lucha no denota solamente los episodios de violencia manifiesta, también se refiere al tránsito entre un modo de lo social a otro (Herzog y Dobon, 2012). Por tanto, cada forma de reconocimiento adquirido es el resultado de una lucha social.

Honneth restituye las consideraciones hegelianas en torno a la lucha, ya sea producto de un delito o de una lucha por honor ${ }^{10}$, y concluye que, en cada nueva

\footnotetext{
${ }^{10}$ Honneth dedica el segundo capítulo de La lucha por el reconocimiento al abordaje de la relación entre delito y eticidad, en particular el autor esboza una conexión de distintos escritos tempranos de Hegel para arribar a la idea de que el delito, en tanto acto destructivo, tiene como origen la experiencia de un reconocimiento incompleto (1997: 32). También las luchas por el honor constituyen un momento
} 


\section{Emilse Toninello}

exigencia, los sujetos adquieren un saber sobre su propia identidad; y al mismo tiempo que adquieren mayor autonomía, debe crecer en ellos la conciencia de una mayor dependencia mutua (1997). En palabras del autor: "[I]os conflictos sociales en que se rompe la eticidad natural ocasionan en los sujetos la emergencia de una disposición a reconocerse recíprocamente, como destinados unos a otros y, no obstante, al mismo tiempo como personas plenamente individualizadas" (1997: 36).

En efecto, es por la vía de la lucha que los sujetos se disponen a reconocerse mutuamente tanto en su especificidad individual como en su interdependencia. Para dar cuenta de aquel lazo ético, Hegel introduce el concepto de solidaridad, que surge en el reencuentro entre los miembros de una comunidad luego de verse aislados por las relaciones jurídicas (Honneth, 1997). De modo que, con su clásico proceder tripartito, Honneth indica que para el joven Hegel

en las relaciones afectivas de reconocimiento de la familia, el individuo humano es reconocido como un ente concreto de necesidades, en las de reconocimiento formal-cognitivo del derecho, lo es como persona abstracta, y en las relaciones emocionalmente ilustradas del Estado, es reconocido como un general concreto, como un sujeto socializado en su unicidad (1997: 38).

Así, las relaciones de solidaridad que caracterizan a la eticidad surgen luego de que las formas amorosas de reconocimiento son presionadas por las formas jurídicas y se extienden hacia formas más plenas de reconocimiento; hacia una forma de solidaridad universal entre los miembros de una comunidad. Es así que,

conflictivo central en el pensamiento hegeliano, ya que allí se presenta una lesión a la integridad de la persona como un todo, en la que ambas personas involucradas están dispuestas a arriesgarse. Se trata aquí del objetivo recíproco de poner a prueba la propia integridad. Dice Honneth: "Hegel no solo quiere mostrar cómo las estructuras de reconocimiento elemental son destruidas por actos de alienación negativa de libertad; quiere mostrar también que solo por tales actos destructivos pueden crearse las relaciones éticamente maduras de reconocimiento, bajo cuyo presupuesto puede desarrollarse después efectivamente una "comunidad de ciudadanos libres»" (1997:36). Sobre la relación entre castigo y delito en la Filosofía del Derecho de Hegel, puede verse Cooper, D. (2016). La teoría hegeliana del castigo. En Pelczynski, Z. (1016). Hegel y lo político. Ciudad Autónoma de Buenos Aires: Prometeo. 
Lucha e institucionalización: dos dimensiones de la justicia social como reconocimiento en el pensamiento de Axel Honneth

[p]ara poder ofrecer al extraño el reconocimiento de una participación solidaria en su curso de vida, de antemano es necesario el empuje de una experiencia que me ilustra acerca de que nosotros, en un sentido existencial, compartimos ciertas amenazas [...] eso se mide a su vez por la representación que tenemos en común sobre una vida feliz en el espacio de la comunidad (1997: 113).

Más tarde, con el giro hacia la filosofía de la conciencia, Hegel desplaza los motivos del desencadenamiento del conflicto al interior del espíritu humano (Honneth, 1997). Aquí el reconocimiento corresponde al proceso mediante el cual una conciencia ya conformada "idealmente" como totalidad "se reconoce a sí misma en otra totalidad semejante", y llega a un conflicto o lucha, porque es "solo por la lesión recíproca de sus pretensiones subjetivas, [que] los individuos pueden lograr un saber acerca de si el otro en cada caso se reconoce en ellos como una totalidad" (Honneth, 1997: 41, el agregado de corchetes es propio). De ese modo el conflicto representa un mecanismo de colectivización social que fuerza a los sujetos a reconocerse recíprocamente. En efecto, la lucha por el reconocimiento es parte de un proceso social por medio del cual se produce un incremento de socialización, en la medida en que se da una descentralización de las formas de la conciencia general (Honneth, 1997). Sin embargo, Honneth señala una limitación en este giro hacia la filosofía de la conciencia en los desarrollos hegelianos. Indica que

le hace perder la idea de una intersubjetividad procesal del hombre y le cierra el camino a aquella otra solución que hubiera consistido en introducir las diferenciaciones necesarias entre los diversos grados de autonomía personal en el espacio mismo teórico- intersubjetivo (1997: 43).

Conforme a la lectura de Honneth, en Realphilosophie -texto que precede a la Fenomenología del Espíritu y donde se consolida la centralidad del concepto de Espíritu, fundamental en la filosofía de la conciencia-, Hegel desplaza su atención de la teoría de la eticidad que venía desarrollando y se concentra en las reflexiones sobre la 


\section{Emilse Toninello}

formación del Espíritu. No obstante, allí introduce la idea -que también puede encontrarse en System der Sittlichkeit- de que en la relación amorosa se confirma la individualidad natural de los sujetos, y se experimentan a sí mismos en tanto seres necesitantes y anhelantes (Honneth, 1997). Honneth señala que: "[s]i esta tesis se generaliza sistemáticamente, resulta la premisa teórica de que el desarrollo de la identidad personal de un sujeto está en principio ligada al presupuesto de determinados actos de reconocimiento de otros sujetos" (1997: 52). Es decir, la formación de la identidad del sujeto depende del reconocimiento intersubjetivo. Si alguna de las partes negara el reconocimiento al otro, no solo se produce la negación sobre aquel, sino que también no le permite la experiencia de reconocimiento propio: la exigencia de reciprocidad está involucrada en toda relación de reconocimiento (Honneth, 1997). Asimismo, Hegel expande el proceso de formación del sujeto introduciendo la esfera del entorno social en sus reflexiones. Allí sostiene, en discusión con las doctrinas del estado de naturaleza, que las relaciones de derecho son relaciones prácticas entre personas, de cuya limitación o determinación de la libertad vacía emergen las relaciones de reconocimiento. En otras palabras, las relaciones de reconocimiento producen derecho, el cual determina o limita la libertad vacía de las personas en su relación con otros sujetos, y hace posible, en definitiva, una autorrealización individual cada vez más cabal (Honneth, 1997). Si bien para Hegel, la experiencia de la muerte ${ }^{11}$ daba lugar a la producción intersubjetiva de derecho, Honneth sostiene que la vulnerabilidad"12 puede ser "esa capa de relaciones de

\footnotetext{
${ }^{11}$ En este punto, Honneth señala tres interpretaciones sobre la experiencia de la muerte como producción intersubjetiva de las relaciones de derecho. Ellas son las ofrecidas por Andreas Wildt, Alexander Kojève y Emmanuel Lévinas. Descartando estas últimas dos, Honneth sostiene: "en la percepción recíproca de su común mortalidad, los sujetos en lucha descubren que ya se han reconocido previamente en sus derechos fundamentales y con ello han creado implícitamente el cimiento social de una relación de derecho intersubjetivamente vinculante" (1997: 65).

${ }^{12}$ Sobre la noción de vulnerabilidad, desde otra perspectiva, ver Butler, J. (2010). Marcos de guerra. Las vidas Iloradas. Buenos Aires: Paidós. En esa línea, los modos en que la vulnerabilidad o precariedad posibilita alianzas entre grupos de personas sufrientes, se encuentra extensamente desarrollado en Butler, J. (2017). Cuerpos aliados y lucha política. Buenos Aires: Paidós. Por caso, el movimiento feminista argentino "Ni una menos" llevó como consigna en 2018 "Vivas, libres y desendeudas", dando cuenta de la articulación de distintas formas de precariedad a las que se encuentran sometidas las mujeres y disidencias. Disponible en http://niunamenos.org.ar/destacada-home/apostasia-feministadecidir-vivas-libres-desendeudadas-nos-queremos/
} 
Lucha e institucionalización: dos dimensiones de la justicia social como

reconocimiento en el pensamiento de Axel Honneth

reconocimiento, cuyo núcleo normativo, en la relación jurídica, toma una forma intersubjetiva vinculante" (1997: 65).

Ahora bien, la esfera de la eticidad (Sittlichkeit) reviste una importancia fundamental desde muy temprano en el pensamiento hegeliano, ya que, "solo en su espacio institucional puede claramente desarrollarse el modo de reconocimiento recíproco gracias al cual la «voluntad singular» del individuo puede obtener confirmación social” (Honneth, 1997: 75, cursivas propias). Es decir, tal como fue mencionado al comienzo de este apartado, la garantía institucional juega un papel central en la realización de la libertad individual, dado que allí se gestan las interacciones sociales caracterizadas por el respeto mutuo que hacen posible que todos y cada uno de los miembros de la comunidad pueda realizar libremente sus planes de vida. En este punto, Honneth toma cierta distancia del planteo original de Hegel, ya que, allí se sostiene que en la esfera ética se transforman todos los elementos de la vida social en componentes de un Estado global (Honneth, 1997). ${ }^{13}$ Honneth advierte que dicha conceptualización cierra a la esfera ética y no le permite dar cuenta de las relaciones positivas que los sujetos establecen entre sí, más allá de las expresiones estatales (1997). Más aún, señala que Hegel, aferrado a esta conceptualización, no llega a dar el paso esperado para poder construir un concepto de lo ético basado en la teoría del reconocimiento.

Una vez enmarcado en la filosofía de la conciencia, Hegel escribe la Fenomenología del Espíritu (2015), donde la lucha por el reconocimiento queda asociada a la formación de la autoconciencia y, bajo la dialéctica del amo y el esclavo, queda anudada a la experiencia de confirmación práctica por vía del trabajo. En palabras de Honneth:

ni el concepto intersubjetivo de la identidad humana, ni la diferenciación entre los distintos medios de reconocimiento, ni la

\footnotetext{
${ }^{13}$ Sobre interpretaciones en torno a la concepción del Estado en la filosofía hegeliana, ver Weil, E. (1996). Hegel y el Estado. Buenos Aires: Leviatán. Pelczynski, Z. (2016). Hegel y lo político. Buenos Aires: Prometeo. Amengual Coll, G. (1989). Estudios sobre la «Filosofía del Derecho» de Hegel. Madrid: Centro de estudios constitucionales. Losurdo, D. (2012). Hegel y la catástrofe alemana. Madrid: Escolar y Mayo Editores.
} 


\section{Emilse Toninello}

diferenciación de las relaciones de reconocimiento gradualmente escalonadas que aquellos introducen, ni sobre todo la idea de un papel históricamente productivo de la lucha moral, vuelven a tener una función sistemática en la filosofía política de Hegel (1997: 81).

A pesar de los laberintos conceptuales que experimenta la idea de reconocimiento en el sistema de pensamiento hegeliano, Honneth asegura que, el reconocimiento puede comprenderse como una confirmación práctica por la cual los sujetos acceden, por la vía conflictiva, a un entendimiento normativo de sí mismos como determinado tipo de persona humana, y por ello, se trata de las condiciones intersubjetivas de la autorrealización de las personas (1997).

Ahora bien, Honneth subraya las dificultades que acarrea tomar las categorías hegelianas en un contexto posmetafísico como el actual (Honneth, 1997, 2016). Por ello, considera útil articular la filosofía de Hegel con los desarrollos de la psicología social realizadas por Georg Mead (1997). Honneth sostiene que es Mead quien podría otorgarle una base psicosocial a la idea de la lucha por el reconocimiento de Hegel. Es que, para Mead, el proceso de desarrollo social consiste en el conflicto que emerge entre los impulsos internos del yo y las normas sociales de comportamiento conforme a sus otros - "el mí" - El resultado de ese proceso desemboca en una ampliación de derechos (Honneth, 1997).

Honneth indica que tanto para Hegel, bajo el concepto de eticidad, como para Mead con la figura del "otro generalizado", se puede considerar que en las relaciones de reconocimiento recíproco los sujetos se ven confirmados en su peculiaridad como personas por cualidades o capacidades específicas (Honneth, 1997). En tal sentido, Mead proporciona una "versión materialista" de la lucha por el reconocimiento de Hegel y contribuye de esa manera a la construcción de una teoría social normativa plena de contenido, empresa central de Honneth, cuyo punto de partida es que la reproducción de la vida social se cumple bajo el imperativo de un reconocimiento recíproco (Honneth, 1997). Es de ese modo que adquieren expresión social las pretensiones ilimitadas de la subjetividad y tiene lugar un proceso de individuación 
Lucha e institucionalización: dos dimensiones de la justicia social como reconocimiento en el pensamiento de Axel Honneth

que se vincula, a su vez, con el proceso de expansión de las relaciones de reconocimiento en las que se encuentra involucrado cada miembro de la comunidad (Honneth, 1997).

A partir de estos desarrollos, susceptibles de ser encontrados en el pensamiento de Hegel como también en los estudios elaborados por Mead, Honneth sustenta la existencia de tres formas diferenciadas de reconocimiento (Honneth, 1997). A saber: el amor, el derecho y la estima o valoración social. Al interior de la esfera del amor, el primer estadio de reconocimiento recíproco, los sujetos se confirman como seres necesitados entre sí. Por medio de los vínculos amorosos, las personas adquieren una elemental confianza en sí mismos que constituye la posibilidad de elaborar posiciones de autorrespeto. De manera que, crea la autoconfianza individual imprescindible para la participación autónoma en la vida pública (Honneth, 1997). Una vez que el individuo se desplaza hacia entornos ajenos a la esfera amorosa, encuentra en el derecho la forma de reconocimiento recíproco que permite una autocomprensión más cabal, en la medida en que se sabe que se tienen que cumplir ciertas obligaciones normativas frente a unos otros con quienes nos encontramos de modo ocasional (Honneth, 1997). A partir de la modernidad

el sistema de derechos puede ser entendido como expresión de los intereses generalizables de todos los miembros de la sociedad, de manera que su pretensión según excepciones y privilegios no debe consentirse [...] penetra en la relación de reconocimiento del derecho una forma de reciprocidad nueva y ambiciosa: los sujetos de derecho se reconocen, porque obedecen a la misma ley, recíprocamente como personas que pueden decidir racionalmente acerca de las normas morales en su autonomía individual (Honneth, 1997: 135).

Es así que, el reconocimiento jurídico le otorga al sujeto la comprensión de que comparte con los demás las facultades para participar de la construcción de la voluntad y la posibilidad de referirse a sí mismo positivamente, esto es lo que Honneth denomina "autorrespeto" (1997: 147). Por último, en la esfera de la valoración o 


\section{Emilse Toninello}

estima social se da una forma de reconocimiento recíproco que se diferencia del amor y del derecho, ya que pone en valor las cualidades particulares que caracterizan a las personas (Honneth, 1997). Este tipo de reconocimiento recíproco supone la existencia de una vida social cohesionada que constituye una comunidad valorativa con objetivos que, aunque variables históricamente, son compartidos por los miembros de dicha comunidad (Honneth, 1997).

No obstante, al interior de la organización social moderna convive una tensión permanente en torno a las interpretaciones culturales sobre lo que se considera públicamente una forma de vida valiosa. Esta lucha permanente encuentra estabilizaciones transitorias cuando alguno de los grupos posee la fuerza de los medios simbólicos y el clima público necesario para lograr aquella estabilidad (Honneth, 1997). En el despliegue de estos conflictos, los sujetos desarrollan una autocomprensión individual que, llamada eticidad por Hegel, Honneth define mediante un principio rector: la solidaridad (1997). El autor sostiene que las relaciones sociales simétricas que tienen lugar en las sociedades modernas son relaciones solidarias ya que se trata de una "participación activa en la particularidad individual de las otras personas [...] pues, solo en la medida en que yo activamente me preocupo de que el otro pueda desarrollar cualidades que me son extrañas, pueden realizarse los objetivos que nos son comunes" (1997: 158).

Ahora bien, cuando el reconocimiento recíproco esperado en todo trato social con otros es negado o privado emergen formas de humillación o menosprecio ${ }^{14}$ que constituyen injusticias, dado que perjudica la libertad de acción de quienes experimentan estas ofensas, y de ese modo se lesiona el entendimiento positivo que las personas tienen de sí mismas a través de las relaciones intersubjetivas que han establecido (Honneth, 1997). La centralidad de la noción de menosprecio radica en que constituye la motivación de la lucha por el reconocimiento, es decir, cuando las personas experimentan una negación de los derechos que consideran merecer como

\footnotetext{
${ }^{14} \mathrm{Al}$ igual que con las formas de reconocimiento, Honneth sostiene que el menosprecio puede ser diferenciado en tres modelos, según el grado de perjuicio que produzca en la autorreferencia práctica de la persona (1997: 161).
} 
Lucha e institucionalización: dos dimensiones de la justicia social como

reconocimiento en el pensamiento de Axel Honneth

miembros de determinada comunidad, se ven lesionadas y empujadas a la búsqueda de acciones que reparen aquel daño (Honneth, 1997). En tal sentido, Honneth sostiene la tesis de que las reacciones negativas cumplen la función de pasaje del sufrimiento a la acción. La vergüenza, la cólera o el desprecio son el tipo de reacciones que, fundadas en la dependencia de las personas respecto de las relaciones de reconocimiento, habilitan la acción cuando se ven excluidas de ellas (Honneth, 1997). Las tensiones que se producen aquí pueden ser disueltas cuando se encuentran nuevos modos de obrar, configurados bajo la forma de la resistencia política (Honneth, 1997). En palabras de Honneth:

[s]olo porque los sujetos humanos no pueden reaccionar de manera sentimentalmente neutra a las enfermedades sociales, como las que representan el maltrato físico, la desposesión de derechos y la indignidad, los modelos normativos de reconocimiento recíproco dentro del mundo de la vida social tienen ciertas posibilidades de realización. Toda reacción negativa de sentimientos que penetra con la experiencia de un desprecio de las pretensiones de reconocimiento contiene en sí de nuevo la posibilidad que al sujeto concernido se le manifieste la injusticia que se le hace y se convierta en motivo de resistencia política (1997: 168-169).

Asimismo, señala Honneth que la debilidad práctica de este planteo consiste en que las reacciones a las injusticias son una posibilidad, y como tal, no tienen un carácter inevitable, en todo caso, su emergencia depende de la constitución del entorno político-cultural. ${ }^{15}$ En suma, es la lucha la que desencadena procesos de reconocimiento intersubjetivo, los cuales constituyen una pieza central en la autorrealización individual, cuya ampliación resulta un elemento clave en la concepción normativa de la justicia social que Honneth propone para las sociedades contemporáneas.

\footnotetext{
15 Al introducir que el paso de la sensación de injusticia o falta de reconocimiento a la acción o resistencia política es tan solo una posibilidad, y no una necesidad, se podría dilucidar que Honneth matiza el carácter teleológico que podría atribuirse a sus desarrollos.
} 


\section{Emilse Toninello}

\section{La institucionalización del reconocimiento.}

La sensación de injusticia social radica, pues, en la frustración de las pretensiones de reconocimiento que experimentan los sujetos. Esto, constituye el núcleo normativo de la teoría de la justicia social de Axel Honneth (Honneth, 2006). Para avanzar sobre su propuesta, es preciso señalar algunas consideraciones elaboradas por el autor en el debate entablado con Nancy Fraser en torno a los conflictos sociales contemporáneos. Allí Fraser ha advertido que las teorías del reconocimiento en tanto autorrealización corren ciertos riesgos, tales como el de portar una idea de vida buena ceñida con el pluralismo de valores presente en nuestras sociedades, caer en psicologicismos, o incluso, justificar los reclamos de reconocimiento de grupos que podrían estimular actitudes discriminatorias hacia las minorías ${ }^{16}$; sin embargo, Honneth sostiene que el marco conceptual otorgado por el reconocimiento logra explicar tanto las causas de los sentimientos de injusticia como los objetivos normativos de los movimientos sociales que luchan por repararlas (Honneth, 2006). Por tanto, para Honneth la sensación de injusticia emerge a partir de la falta de reconocimiento, y de allí se sigue que es mediante el reconocimiento que se obtienen relaciones sociales justas.

En su respuesta a Fraser, y bajo la influencia de la Filosofía del Derecho (2017), Honneth retoma sus elaboraciones de La lucha por el reconocimiento (1997) y sostiene que es posible diferenciar tres esferas de reconocimiento recíproco donde los sujetos encuentran la posibilidad de autorrealizarse. En primer lugar, señala que en la esfera del amor los individuos, en tanto seres necesitados, se atienden mutuamente en función de su bienestar individual. Seguidamente, en la esfera de la igualdad jurídica, las personas buscan ser igualmente respetadas en sus derechos. Finalmente, en la esfera del éxito los sujetos, quienes gozan de ciertas habilidades y facultades socialmente valiosas, esperan ser reconocidos por sus logros particulares (Honneth,

\footnotetext{
16 Por razones de espacio, aquí no se abordan en profundidad los contrapuntos trazados por Fraser y Honneth. Para mayor precisión ver Fraser, N. y Honneth, A. (2006). ¿Redistribución o reconocimiento? Madrid: Moratta.
} 
Lucha e institucionalización: dos dimensiones de la justicia social como reconocimiento en el pensamiento de Axel Honneth

2006). ${ }^{17}$ Erigida la diferenciación de las esferas, Honneth indica que cada forma de reconocimiento contiene un principio normativo interno. Con ello se distancia de los desarrollos de la Filosofía del Derecho en dos aspectos. Por un lado, los conflictos que sobrevienen al interior de las esferas no se presentan en virtud de la transición de una hacia otra, sino que en cada una de ellas se da una disputa en torno a la aplicación legítima de su principio rector. Por otro lado, Honneth abandona los complejos institucionales propuestos por Hegel (Familia, Estado) ya que esto constituiría una limitación para analizar otros modos de encarnación institucional donde también están presentes estas formas de reconocimiento, tales como la amistad en la esfera del amor o los derechos sociales en la esfera del éxito (Honneth, 2006).

A estas consideraciones, Honneth añade la idea de que cada esfera de reconocimiento detenta un exceso de validez, dado que es posible que quienes sufran faltas de reconocimiento puedan reivindicar racionalmente los principios subyacentes de otras esferas con el objetivo de adquirir un trato mejorado en términos sociales. Solo así es posible el progreso para la sociedad, ya que como señala el autor,

todas las luchas por el reconocimiento progresan a través de una interpretación de la moral dialéctica de lo universal y lo particular: siempre se puede apelar a favor de una determinada diferencia relativa, aplicando un principio general de reconocimiento mutuo que obligue normativamente una expansión de las relaciones vigentes de reconocimiento (Honneth, 2006: 121, cursivas propias).

Por tanto, ya sea que las demandas se centren en cuestiones materiales o en aspectos simbólicos, la motivación de las exigencias de reconocimiento se funda sobre una base moral: cuando se tiene la sensación de no recibir lo que se considera justo, los sujetos demandan una reconfiguración de los entramados del reconocimiento institucionalizado, ya sea apelando a una negociación política, bajo el principio de la igualdad jurídica o apelando a la valoración de los propios logros, bajo el principio del

\footnotetext{
$17 \mathrm{Si}$ bien en La lucha por el reconocimiento, Honneth nombra las esferas como: amor-derechosolidaridad, en adelante, especialmente en el debate con Nancy Fraser, modifica la nominación a: amorigualdad jurídica-éxito/logro.
} 


\section{Emilse Toninello}

éxito (Honneth, 2006). En efecto, Honneth sostiene que las expectativas normativas de los sujetos se encuentran guiadas por la búsqueda de reconocimiento social, que se desarrolla en dos direcciones: hacia una socialización moral del sujeto y hacia una integración moral de la sociedad. Esta última supone un "proceso de inclusión a través de formas estables de reconocimiento" (Honneth, 2006: 135). Dicho proceso de integración, donde se legitiman las estructuras sociales en tanto garantizan relaciones fiables de reconocimiento mutuo, se produce por la institucionalización de los principios de reconocimiento (Honneth, 2006). De modo que

[I]a justicia o el bienestar de la sociedad debe ser proporcionado a su capacidad de asegurar las condiciones de reconocimiento mutuo en las que la formación de la identidad personal y, en consecuencia, la autorrealización individual pueda desarrollarse de manera adecuada (Honneth, 2006: 136).

En otras palabras, es en las instituciones y su flexibilidad para reconfigurarse en función de las demandas de reconocimiento de los sujetos, que la integración social tiene lugar, entendida como proceso que busca extender las estructuras sociales que garantizan la autorrealización de las personas. Así, tal como fue mencionado previamente, cuando los sujetos luchan por el reconocimiento social, cuya ausencia experimentan como un agravio moral a su desarrollo personal, se apela al excedente de validez que cada esfera posee $y$, en la medida en que dicho reconocimiento se obtiene, se incrementa la calidad de la integración social: hay allí progreso moral (Honneth, 2006). Por tanto, la concepción de justicia sustentada por Honneth se encuentra estrechamente ligada a una idea de vida buena ${ }^{18}$, cuyo punto de referencia es la calidad de las relaciones sociales de reconocimiento (Honneth, 2006).

\footnotetext{
${ }^{18}$ Tal como fue anticipado, aquí se presenta una diferencia fundamental con el planteo de Nancy Fraser, quien no precisa ninguna concepción de vida buena, sino que apunta a la idea de participación igualitaria de los miembros de una sociedad y desde allí cuestiona la "sobre carga ética de la teoría del reconocimiento". A diferencia de la propuesta de Honneth, que según la autora coloca el reconocimiento en el plano de lo ético, Fraser asocia el reconocimiento, no con la posibilidad de los sujetos de realizarse personalmente sino con lo que ha denominado el modelo de estatus, y la falta de reconocimiento o el reconocimiento erróneo, queda vinculado con la subordinación a la que se ven
} 
Lucha e institucionalización: dos dimensiones de la justicia social como reconocimiento en el pensamiento de Axel Honneth

En suma, para Honneth la justicia social consta de tres principios orientadores amor, igualdad jurídica y éxito- igualmente importantes, bajo los cuales es posible el desarrollo de la identidad personal de los sujetos, es decir la autorrealización individual. En la medida en que los miembros de una comunidad encuentran reconocidas sus demandas y logran realizar sus planes de vida en el marco del respeto y la estima social, es que las relaciones de reconocimiento ganan en calidad y la sociedad progresa moralmente (Honneth, 2006). Dicho de otro modo, aquellos tres principios de reconocimiento recíproco constituyen el núcleo normativo de la justicia social. Una teoría de la justicia social que se enmarca en una concepción global de progreso, cuya medida está basada en dos criterios: por una parte, cuando se incrementan los procesos de individuación, esto es, cuando el sujeto conquista el reconocimiento de sus logros como algo diferenciado de los logros de otros; y, por otra parte, los procesos de inclusión, referidos a las mejoras en las condiciones sociales de los miembros de una comunidad. Por ello, dice Honneth

la tarea crítica de una concepción de justicia en el marco de la teoría del reconocimiento no tiene que limitarse a una apelación a este exceso de validez específico de cada esfera, sino que también puede incluir el examen de las líneas de demarcación entre las esferas (Honneth, 2006: 145, cursivas propias).

Por tanto, se hace justicia cuando los sujetos incrementan la calidad de las relaciones de reconocimiento mutuo tanto hacia el interior de cada esfera como en la revisión de los límites establecidos entre ellas.

Ahora bien, el énfasis en la dimensión institucional se encuentra pormenorizadamente trabajada en El derecho de la libertad (2014), uno de los últimos

sometidas las personas cuando las instituciones sociales se rigen por normas culturales que no permiten una interacción en pie de igualdad. Por ello, Fraser sostiene que el reconocimiento, lejos de ser una cuestión ética, es una cuestión de justicia que puede ser evaluada por la noción de paridad participativa (Fraser y Honneth, 2006). 


\section{Emilse Toninello}

libros publicados por Axel Honneth. ${ }^{19}$ Allí, desarrolla in extenso las tres concepciones de la libertad que, según Honneth, han tenido mayor relevancia en el pensamiento político moderno, a efectos de demostrar que cada idea de libertad contiene un abordaje distinto de la justicia social (Honneth, 2014). En primer lugar, la noción de libertad negativa, que remite al pensamiento hobbesiano -y que han continuado John Locke, John Stuart Mill pero también Robert Nozick y, según Honneth, Jean Paul Sartre-, comprende que un hombre es libre en la medida en que no encuentra obstáculos para llevar a cabo su acción. De modo que, el hombre queda representado como un ser atómico, lo cual conduce, necesariamente, a un modelo de justicia que promueve un ordenamiento social egoísta (Honneth, 2014). Sin embargo, a partir de las reflexiones de Jean Jacques Rousseau es posible avizorar una segunda idea de libertad, denominada por Honneth como "reflexiva", caracterizada por la capacidad del individuo de tomar sus propias decisiones de acuerdo con su voluntad. Honneth indica que existen, al menos, dos interpretaciones de este tipo de libertad: una vinculada con la idea de autonomía, cuyo exponente máximo fue Immanuel Kant; y otra, asociada a la noción de autorrealización, impulsada por Johann Herder. Ambas sostienen que los actos libres son producto de un logro reflexivo del sujeto (Honneth, 2014).

Si bien es posible derivar de la concepción de la libertad negativa un determinado modelo de justicia, cabe señalar que de las dos interpretaciones de la libertad reflexiva también se siguen diversos abordajes de la justicia social. Para la libertad reflexiva entendida como autodeterminación, la justicia social se trata de la concurrencia de todos los ejercicios individuales de la libertad, es decir, es un procedimiento por el cual se construye una voluntad común, bajo condiciones de igualdad, y por medio del cual los ciudadanos deciden sobre los principios del orden social justo. ${ }^{20}$ En otras palabras, bajo la figura de la autonomía moral se construye un

\footnotetext{
${ }^{19}$ Luego de esta publicación, Axel Honneth responde algunas observaciones en torno a las posibilidades de transformación social que su enfoque podría brindar en su libro La idea del socialismo (2017), cuya publicación original es de 2015.

20 Tal como fue mencionado, esta línea abierta por Kant es retomada tanto por John Rawls como por Jürgen Habermas.
} 
Lucha e institucionalización: dos dimensiones de la justicia social como

reconocimiento en el pensamiento de Axel Honneth

sistema social de cooperación o deliberación democrática. Sin embargo, si la libertad reflexiva se comprende como autorrealización, la justicia es aquel sistema mediante el cual todo sujeto puede autorrealizarse sin perjudicar a los demás. A diferencia de la noción procedimentalista de las ideas de autonomía, la libertad como autorrealización tiene una elaboración sustancial, y no solo procedimental, de las condiciones sociales requeridas para el ejercicio de la libertad individual (Honneth, 2014). En palabras del autor:

a partir de los conceptos presupuestos de la libertad reflexiva, ya sea del de la autodeterminación o del de la autorrealización, se derivan ideas acerca de qué condiciones institucionales serían necesarias para permitir a todos los individuos el ejercicio de su propia libertad (Honneth, 2014: 62).

No obstante, resulta necesario señalar que si bien la libertad reflexiva no puede desplegarse sin tener en cuenta las condiciones institucionales que la posibilitan, Honneth advierte que hasta aquí esas condiciones institucionales habían sido agregadas posteriormente, es decir, como elementos externos que se incorporan a la justicia social, y no como un momento interno de su realización. Solo volviendo a Hegel, dice Honneth, es posible concebir el modo en que ciertas instituciones constituyen los medios para la realización de la libertad (Honneth, 2014).

Según Honneth, es en la Filosofía del derecho donde Hegel desarrolla sus críticas a las dos nociones de libertad y postula un tercer modelo que supere las deficiencias de sus predecesores. Honneth llama a este tercer modelo "libertad social", que "se basa en una idea de instituciones sociales según la cual los sujetos se relacionan unos con otros de manera tal que pueden concebir a su contraparte como otro de sí mismos" (Honneth, 2014: 67). Aquí, la clave de la experiencia de la libertad está estrechamente vinculada con la posibilidad de verse confirmado en otros, es decir, cuando se da un reconocimiento mutuo. De esa manera, se amplía la concepción de la libertad y adquiere un carácter necesariamente intersubjetivo. En definitiva, la libertad social es aquella libertad que se realiza a través del reconocimiento 


\section{Emilse Toninello}

intersubjetivo de los compañeros de interacción y que se encuentra garantizada por instituciones sociales. La existencia de las instituciones como garantía para la realización de la libertad constituye un punto nodal para Honneth en su empresa de reactualización del pensamiento político de Hegel. Ya que,

«libre» es en último término el sujeto solo cuando en el marco de prácticas institucionales se encuentra con una contraparte a la cual lo conecta una relación de reconocimiento mutuo, porque puede ver en las metas de este una condición de la realización de las propias metas (Honneth, 2014: 68).

En tal sentido, Honneth destaca dos tareas que tienen las instituciones al interior de la teoría hegeliana de la libertad. Por un lado, deben facultar a los individuos para comprender intersubjetivamente sus libertades. Por otro lado, deben ser los medios que le permiten a los sujetos la comprensión de que sus objetivos se realizan de un modo complementario al objetivo de los demás (Honneth, 2014). Por ello, no se trata de cualquier institución la que garantiza la realización de la libertad, sino aquellas que posibilitan la realización mutua de los objetivos individuales a partir de las relaciones de reconocimiento. Ahora bien, el conjunto de instituciones que garantizan a los sujetos la experiencia de la libertad recibe en Hegel -y Honneth conserva el términoel nombre de "eticidad". Dice Honneth que "solo con esta categoría se delinea en último término cómo se puede garantizar la justicia social bajo las condiciones del ideal moderno de libertad" (2014: 83). De modo que, el orden es justo cuando los sujetos pueden realizar su libertad en relación con otros, y pueden hacerlo solo cuando un complejo institucional le garantiza las condiciones para su ejercicio. Esto implica que las condiciones sociales de la justicia no son posteriores a la libertad de los sujetos, antes bien, solo en las instituciones sociales puede una persona encontrar las prácticas que le posibiliten desarrollarse libremente. Honneth subraya que Hegel ha incorporado en su concepción de la justicia la posibilidad de verificar individualmente si las instituciones establecidas satisfacen sus pretensiones de reconocimiento y sostiene que 


\title{
Lucha e institucionalización: dos dimensiones de la justicia social como reconocimiento en el pensamiento de Axel Honneth
}

\author{
tanto la institución de la «libertad del derecho» como también la \\ institución de la «verificación de la conciencia» [...] deben ofrecer a los \\ sujetos la oportunidad, garantizada por el Estado, si fuera necesario, de \\ tomar distancia de todas las relaciones de reconocimiento a las que \\ deben su libertad social (2014: 84).
}

Esto denota que, a pesar de la magnitud del papel de las instituciones sociales, las acciones individuales no quedan obturadas en el pensamiento hegeliano. Los momentos del derecho abstracto y la moralidad en su Filosofía del derecho, dan cuenta de la necesidad tanto de no descartarlos como de no unilateralizarlos, ya que hipostasiar uno u otro de los momentos conlleva peligros que solo con la comprensión social de la libertad pueden ser eludidos (Honneth, 2014) ${ }^{21}$.

En suma, el modelo de libertad social que se desprende de las reflexiones hegelianas, al igual que los modelos de la libertad negativa y la libertad reflexiva, conduce a una idea de justicia que se aleja de la comprensión tradicional. Aquí, la libertad se trata de la realización, cada vez más amplia, de los propósitos individuales de un sujeto en tanto logran ser promovidos por los propósitos de los demás. Por tanto, la justicia se realiza cuando todos los sujetos puedan participar en igual medida en las instituciones de reconocimiento. Honneth sostiene que el centro de la idea de la justicia social radica en que

\footnotetext{
${ }^{21}$ Más adelante, Honneth indica: " No disponemos de una gran parte de las libertades individuales, que deberían ser el prototipo de una idea contemporánea de justicia social, porque tengamos un derecho garantizado por el Estado sobre ellas; antes bien, ellas se deben a la existencia de un enmarañado entramado de prácticas y costumbres armonizadas de débil institucionalización, que nos proporcionan la experiencia de confirmación social o de una enajenación no forzada de nosotros mismos" (2014: 96). Sin embargo, sobre el final del libro, en la parte dedicada a la eticidad democrática, concluye que la esfera de la construcción de la voluntad democrática tiene una posición superior respecto de las otras dos por dos razones: porque dispone de los recursos constitucionales necesarios para fijar los resultados sociales en la forma de garantías jurídicas y porque es el lugar donde es posible la autotematización reflexiva a través del intercambio de argumentos entre los sujetos. Así tiene prioridad por su capacidad de poner en discusión temas que se encontraban fuera de lo socialmente debatido (Honneth, 2014). Resulta evidente, aquí y en otros fragmentos de la obra de Axel Honneth, las tensiones respecto del rol del Estado en la realización de la libertad. Ver también Fraser, N. y Honneth, A. (2006). ¿Redistribución o reconocimiento? Un debate filosófico-político. Madrid: Morata.
} 


\section{Emilse Toninello}

determinadas instituciones, de mucho contenido normativo $y$, por tanto, denominadas «éticas», necesitan de la garantía jurídica, de la protección estatal y del apoyo de la sociedad civil; solo en un juego en el que se reparten las tareas el derecho, la política y lo público social pueden mantenerse vivos aquellos aparatos institucionales a los que los miembros de una sociedad deben las distintas facetas de su libertad intersubjetiva y así, globalmente, la cultura de la libertad (2014: 88).

Justicia social, reconocimiento e intersubjetividad quedan anudadas éticamente a la idea de libertad social, la cual requiere de instituciones mediadoras que les permitan a los sujetos realizar sus planes de vida, comprender que solo pueden hacerlo con otros y tematizar en el debate público los asuntos que consideran injustificadamente negados o insuficientemente reconocidos.

\section{Consideraciones finales}

A modo de cierre, es posible arribar a una conclusión en doble sentido. El primero se vincula con la reconstrucción de la comprensión de Axel Honneth de la justicia social como reconocimiento. El segundo, se trata de la identificación de las dos dimensiones que coparticipan en la realización de la justicia social, en tanto reconocimiento. De modo que, se podría sostener que la teoría de la justicia social de Axel Honneth se encuentra determinada por las tres esferas de reconocimiento que caracterizan el orden institucionalizado de la sociedad capitalista burguesa. Es en el amor, el derecho y el éxito donde los sujetos entablan relaciones de reconocimiento recíproco que habilitan su autorrealización, y donde emerge, además, la posibilidad de un borramiento de los límites entre las esferas, el exceso de validez -tal como fue denominado por el autor-, cuya expansión permite el progreso moral de nuestras sociedades por una doble vía: una mayor individualización y, al mismo tiempo, una mayor inclusión social. Entonces, hay progreso moral solo cuando las relaciones de reconocimiento, al interior de las esferas y entre ellas, se incrementan y se intensifican. Es así como se avanza hacia un ordenamiento socialmente justo. 
Por un lado, tal como fue abordado en el primer apartado, la justicia social se encuentra ligada a la idea de reconocimiento como el resultado de una lucha que los sujetos emprenden a los fines de obtener lo que consideran moralmente justificado. De allí se desprende que toda exigencia de reconocimiento contiene implícitamente un carácter intersubjetivo, dado que, sin la confirmación de los compañeros de interacción social, no es posible satisfacer las demandas emitidas por los sujetos o grupos sociales. Por tanto, el reconocimiento en tanto lucha ilumina la comprensión de la motivación de los conflictos sociales, cuyo despliegue conduce a un ordenamiento más justo de la sociedad.

Por otro lado, en el segundo apartado, se ha subrayado la importancia de la dimensión institucional en los planteos de Honneth. Para el autor, sin las condiciones sociales que garanticen la realización de la libertad de los miembros de una comunidad, no es posible un orden político justo. Por eso, el aseguramiento que otorgan las instituciones es reafirmado en la teoría de Honneth, sostenido por un modelo de libertad que ha dado en llamar social. En dicho modelo, la garantía jurídica, la protección estatal y el apoyo social son tres instancias institucionales fundamentales para la realización de la justicia social como reconocimiento intersubjetivo.

De modo que, para Honneth siguiendo a Hegel, un orden justo es aquel donde los sujetos logran autorrealizarse mediante relaciones de reconocimiento recíproco, cada vez de mayor calidad, garantizadas institucionalmente: la realización de la justicia social se conecta, necesariamente, con la autorrealización individual. Si bien, en los estudios de Honneth se pone de manifiesto que las tres esferas diferenciadas de reconocimiento recíproco constituyen el núcleo normativo de la justicia social, es posible añadir que ese núcleo normativo cuenta también con dos dimensiones: la dimensión de la lucha por el reconocimiento y la dimensión de la institucionalización del reconocimiento. Así dicho, sería posible objetar cierta desconexión entre estos dos momentos, sin embargo, aquí se sostiene que en la obra de Honneth es visible el modo en que ambas dimensiones corren entrelazadas. 


\section{Emilse Toninello}

Tal como fue mencionado previamente, ciertas críticas dirigidas a El derecho de la libertad (2014), han remarcado un desplazamiento de la centralidad del conflicto por parte de Honneth, dándole mayor importancia a la dimensión institucional, lo que implicaría una desatención al concepto de lucha (Abril, 2016); aquí se sostiene la idea de la coexistencia de dos tiempos en la teoría de Axel Honneth, ya que, es posible advertir la relevancia de la vida institucional desde los trabajos más tempranos del autor como también la permanencia de la dimensión conflictiva en sus últimos trabajos. Dicho desplazamiento respondería más a una necesidad analítica: la lucha, que fue extensamente tratada en los escritos de las décadas 80 y 90, permanece en las reflexiones del autor; empero, ahora se dedica en detalle al estudio de una de las dimensiones que había sido advertida pero no desarrollada: las instituciones sociales.

En efecto, si se admite que su tesis de habilitación La lucha por el reconocimiento (1997) constituye el mayor exponente de la centralidad del concepto de lucha, se debe señalar también que allí pueden encontrarse, aunque con matices, rastros del papel que desempeñan las instituciones en el despliegue de las relaciones de reconocimiento mutuo. Por otro lado, en el escrito donde se presume el abandono del conflicto, El derecho de la libertad (2014), se puede advertir su presencia en la reconstrucción normativa de un análisis pormenorizado de las luchas sociales que dieron lugar a la construcción de la voluntad democrática, evidenciando la relevancia que dichas luchas tuvieron para la realización de la libertad, garantizada institucionalmente. En suma, la realización de la justicia social conjuga la expansión e intensificación de las relaciones de reconocimiento en las tres esferas, en dos dimensiones coextensivas: lucha e institucionalización. 
Lucha e institucionalización: dos dimensiones de la justicia social como

reconocimiento en el pensamiento de Axel Honneth

\section{Bibliografía}

Abril, F. (2016). El problema de la dominación en El derecho de la libertad de Axel Honneth. Revista Pilquen (19), 1, pp. 1-12.

Amengual Coll, G. (1989). Estudios sobre la «Filosofía del Derecho» de Hegel. Madrid: Centro de estudios constitucionales.

Aristóteles. (2007). Política. Buenos Aires: Alianza.

Butler, J. (2010). Marcos de guerra. Las vidas lloradas. Buenos Aires: Paidós.

-------- (2017). Cuerpos aliados y lucha política. Buenos Aires: Paidós.

--------- (2012). Sujetos del deseo. Reflexiones hegelianas en la Francia del siglo XXI. Buenos Aires: Amorrortu.

(2017). Deshacer el género. España: Paidós.

Honneth, A. (2006). Redistribución como reconocimiento. Respuesta a Nancy Fraser. En Fraser, N. y Honneth, A. (2006). ¿Redistribución o reconocimiento? Un debate político-filosófico. Madrid: Morata.

Hegel, G. W. F. (2015). Fenomenología del Espíritu. Buenos Aires: Fondo de Cultura Económica.

(2017). Fundamentos de la Filosofía del Derecho o Compendio de Derecho Natural y Ciencia Política. Madrid: Tecnos.

Herzog, B. y Hernández I Dobon, F. (2012). La noción de «lucha» en la teoría de reconocimiento de Axel Honneth. Sobre la posibilidad de subsanar el «déficit sociológico» de la Teoría Crítica con la ayuda del Análisis del Discurso. Política y Sociedad, (49), 3, pp. 609-623.

Hobbes, T. (2007). Leviatán. Buenos Aires: Losada. 


\section{Emilse Toninello}

Honneth, A. (1997). La lucha por el reconocimiento. Por una gramática moral de los conflictos sociales. Barcelona: Crítica.

(2009). Crítica del agravio moral. Patologías de la sociedad contemporánea. Buenos Aires: Fondo de Cultura Económica.

-- (2014). El derecho de la libertad. Esbozo de una eticidad democrática. Buenos Aires: Katz.

- (2016). Patologías de la libertad. Buenos Aires: Las cuarenta. - (2017). La idea del socialismo. Buenos Aires: Katz.

Kant, I. (2009). Crítica de la razón pura. México: Fondo de Cultura Económica.

Kojève, A. (2013). Introducción a la lectura de Hegel. Madrid: Editorial Trotta.

Losurdo, D. (2012). Hegel y la catástrofe alemana. Madrid: Escolar y Mayo Editores.

Nosetto, L. y Wieczorek, T. (2020). Métodos de teoría política. Un manual. Ciudad Autónoma de Buenos Aires: Universidad de Buenos Aires. Instituto de Investigaciones Gino Germani.

Pelczynski, Z. (2016). Hegel y lo político. Buenos Aires: Prometeo.

Penchaszadeh, A. P. (2011). El legado griego. Democracia, justicia y anarquía: ¿̇razones de un amor o genealogía de un odio? Anacronismo e Irrupción. Revista de teoría y filosofía política clásica y moderna, (1) 1, pp. 66-82.

Platón. (2009). República. Buenos Aires: Eudeba.

Raffin, M. (2012). El problema de la justicia en la primera modernidad: en torno de las elaboraciones de Spinoza, Leibniz y Kant. Anacronismo e Irrupción. Revista de teoría y filosofía política clásica y moderna, (2) 2, pp. 105-128. 
Lucha e institucionalización: dos dimensiones de la justicia social como

reconocimiento en el pensamiento de Axel Honneth

Rawls, J. (2018). Teoría de la justicia. Buenos Aires: Fondo de Cultura Económica.

Ricouer, P. (2006). Caminos del reconocimiento. Tres estudios. México: Fondo de Cultura Económica.

Sabine, G. (1982). Historia de la teoría política. México: Fondo de Cultura Económica.

Siep, L. (2011). La lucha por el reconocimiento. La relación entre Hegel y Hobbes en los escritos de Jena. Estudios de Filosofía, 43, pp. 31-84.

Strauss, L. (2014). ¿Qué es la filosofía política? Madrid: Alianza Editorial.

Vázquez Prieto, J. (2011). Un concepto equívoco. Sobre la pluralidad de sentidos de la justicia en la obra política hobbesiana. Anacronismo e Irrupción. Revista de teoría y filosofía política clásica y moderna, (1) 1, pp. 83-116.

Weil, E. (1996). Hegel y el Estado. Buenos Aires: Leviatán. 